\title{
Hypoxia of Rats Subjected to Carotid Artery Ligation Results in Impaired Neurogenesis and Reduced Number of Cortical Neurons
}

\author{
YOONYOUNG CHUNG ${ }^{1}$, HANBIT $\mathrm{CHO}^{2}$, GYEONG HYEON JO$^{2}$ and YONGHYUN JUN ${ }^{1}$ \\ ${ }^{1}$ Department of Anatomy, School of Medicine, Chosun University, Gwang-ju, Republic of Korea; \\ ${ }^{2}$ School of Medicine, Chosun University, Gwang-ju, Republic of Korea
}

\begin{abstract}
Background/Aim: Cerebral ischemia is a major cause of abnormal brain development. In a cerebral ischemia model, periventricular leukomalacia $(P V L)$, white matter lesion and a decrease in the number of subcortical neurons were observed. The aim of this study was to investigate the effect of hypoxia on neurogenesis and cell survival. Materials and Methods: In seven-day postnatal rats, the right carotid artery was ligated. The rats were incubated either in a regular normoxic chamber (control group) or in a hypoxic chamber (PVL group, $8 \% 02$ and $92 \%$ N2 at $37^{\circ} \mathrm{C}$ ) for $2 \mathrm{~h}$. Nestin- and NeuN-positive neurons were detected by immunohistochemistry. Results: The densities of nestin-immunoreactivity (IR) cells in the cerebral parietal cortex and subventricular zone were increased with hypoxia. NeuN-IR cells in the cerebral cortex were significantly decreased in the PVL group. Conclusion: Perinatal white matter injury induced neurogenesis, while the survival of neurons was decreased in the cerebral cortex.
\end{abstract}

Abnormal brain development often occurs in premature infants (1). It has been associated with serious clinical problems including cerebral palsy, as well as cognitive, learning and behavioural deficits (2-4). Premature infancy has recently become more prevalent (5). Periventricular leukomalacia (PVL) is the most common form of brain damage in preterm infants (6). It is characterized by cerebral

This article is freely accessible online.

Correspondence to: Yonghyun Jun, Department of Anatomy, School of Medicine, Chosun University, 375 Seosuk-dong, Dong-Gu, Gwangju 501-759 Republic of Korea. Tel: +82 10 28862973, Fax: +82062 2341474, e-mail: jyh1483@chosun.ac.kr

Key Words: Hypoxia, cortex, subventricular zone (SVZ,) nestin, neuronal nuclei (NeuN). white matter damage and considered to play a role in cerebral palsy (7). It is defined as coagulative necrosis and hemorrhagic necrosis and diffuse gliosis in the periventricular region with microglial activation in the cerebral white matter (8).

Periventricular leukomalacia induced by hypoxia-ischemia has been suggested as a major cause of abnormal brain development (9). Total brain volume and weight are reduced by ischemic insult (10). Maturation of myelin was impaired in one neonatal rat model with hypoxia-induced PVL (11). Hypoxia also affected neurogenesis, which is the process of generation of new neurons from progenitor stem cells (12). Neuronal cell proliferation was reduced in the subventricular zone (SVZ) (13), and cortical neuron density was decreased by hypoxia (14). Cell apoptosis was triggered after a $24-\mathrm{h}$ hypoxic insult (15).

As mentioned above, periventricular leukomalacia was associated with white matter injury. Moreover, subcortical neuron density was decreased in the same model (16). Even though neurons of the cortex are affected by hypoxia, cortical lesions remain poorly understood. In this study, we investigated the effect of hypoxia on the survival of neurons and neurogenesis by immunocytochemistry.

\section{Materials and Methods}

In vivo animal PVL model. The use of certified Sprague-Dawley (SD) rats (Damul Laboratory Animals, Daejeon, Republic of Korea) was approved by the Chosun University Institutional Animal Care and Use Committee (approval no. CIACUC2016-S0002). PVL was induced by previously described methods (17). Seven day old, SD rats $(n=18)$ were anaesthetized with Zoletil $(10 \mathrm{mg} / \mathrm{kg}$; Virbac, Nice, France) and xylazine ( $0.15 \mathrm{mg} / \mathrm{kg}$; Bayer, Leverkusen, Germany). Skin and musculature of the cervical region were incised to expose the right carotid artery, which was ligated with skin sutures. The incision site was closed, and the rats rested for $10 \mathrm{~min}$ before incubation in a hypoxic chamber $\left(8 \% \mathrm{O}_{2}\right.$ and $92 \% \mathrm{~N}_{2}$ at $\left.37^{\circ} \mathrm{C}\right)$ for $2 \mathrm{~h}$. Rats who underwent the hypoxic procedure were in the PVL group and rats exposed to normal conditions constituted the control group $(n=18)$. 


\section{Control}

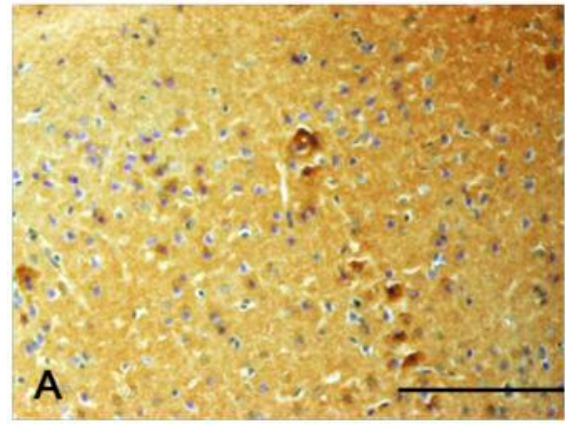

\section{PVL}

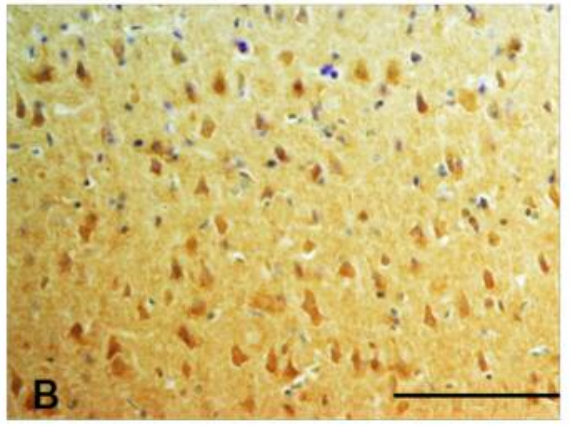

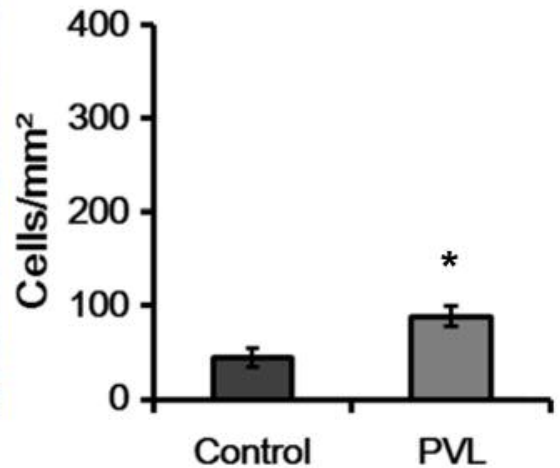

Figure 1. Representative photographs $(A)$ and density $(B)$ of nestin-immunoreactivity $(I R)$ cells in the cerebral parietal cortex. Nestin-IR cells in $P V L$ groups were stained strongly. The data are expressed as mean and SEM values. ${ }^{*} p<0.05$. Scale bars $=100 \mu \mathrm{m}$.

Tissue preparation. Seven days after incubation, rats were sacrificed and their brains were harvested for analysis. The brains were kept in $4 \%$ paraformaldehyde (PFA) at $4^{\circ} \mathrm{C}$ for one day and were then washed in staining jars with distilled water. Dehydration and clearing were performed with gradient ethanol (70\%-100\%) and xylene. The cerebrums were embedded in paraffin and cut serially into $7 \mu \mathrm{M}$ sections in the sagittal plane. The sections were mounted on gelatin-coated slides (Fisher Scientific, Pittsburgh, PA, USA).

Immunohistochemistry. The sections were deparaffinized in xylene and ethanol solutions (100\%-70\%) and washed in $0.1 \mathrm{M}$ phosphatebuffered saline (PBS; pH 7.4). The antigen retrieval procedure was performed with $0.01 \mathrm{M}$ sodium citrate buffer $(\mathrm{pH} 6.0)$ and heating in a microwave oven. After cooling, the slides underwent endogenous peroxidase blocking with $0.3 \%$ hydrogen peroxide for $20 \mathrm{~min}$. Slides were incubated with the primary antibodies overnight at $4^{\circ} \mathrm{C}$ including mouse anti-hexaribonucleotide-binding protein- 3 (NeuN; 1:100, Millipore) and nestin (1:200, Millipore). The next day, the slides were washed with PBS and incubated with a second antibody, which would bind to the primary antibody. The immunoreactivity was visualised with DAB Peroxidase (HRP) Substrate Kit, 3,3'-diaminobenzidine (Vector Laboratories, Burlingame, CA, USA). Thionin was utilised for counterstaining. Coverslips and PolyMount (Polysciences, Warrington, PA, USA) were applied for mounting the sections onto slides.

Statistical analysis. The nestin and NeuN-immunoreactive (IR) cells were quantified using ImagePro Plus software (Media Cybernetics). All of the experimental data were analysed using Statistical Package for Social Sciences (Information Analysis Systems, SPSS, USA). All quantified measurements were compared between the control and hypoxic groups using Student's $t$-tests. The statistical significance was set at $p<0.05$.

\section{Results}

Nestin immunoreactivity. The density of nestin- IR cells in the cerebral parietal cortex was increased in the PVL group when compared to that in the control group (Figure 1). Similarly, the density of nestin-IR cells in the SVZ, defined as the neurogenic zone, was significantly greater in the PVL group than in the control group (Figure 2).

NeuN immunoreactivity. The density of NeuN-IR cells in the cerebral cortex was significantly decreased in the PVL group as compared to that in the control group (Figure 3). In the SVZ, a few NeuN-IR cells were detected. The density of NeuN-IR cells did not differ significantly $(p>0.05)$ between the PVL group and the control group (Figure 4).

\section{Discussion}

We measured the densities of nestin- and NeuN-IR cells in the SVZ and cerebral cortex. The SVZ is capable of neurogenesis (18), which is characterized by cell proliferation, migration, maturation, and survival (19). Neuronal stem cells in the SVZ migrate to the cerebral cortex via the rostral migratory stream (20).

Nestin is a marker of neuronal progenitor cells in the developing brain and has been used to distinguish undifferentiated from differentiated cell types $(21,22)$. It is expressed in very immature or incompletely differentiated cells, including cells of the primitive streak and Henson node (23). In our study, the density of nestinIR cells in the SVZ was increased with hypoxic injury. Some PVL studies have used nestin as a stem cell marker (24). Okoshi et al. showed increased nestin expression in the white matter adjacent to VPL lesions (25). SVZderived glial progenitor cells were considered to be selfrenewing sources in neonatal rats with PVL (26). It was suggested that the early stage of neurogenesis is triggered in the SVZ in the PVL model. Interestingly, the density of nestin-IR cells in the cerebral cortex was also increased. A study by Fagel also observed newly-generated cortical cells under hypoxic conditions (27). It was suggested that 


\section{Control}

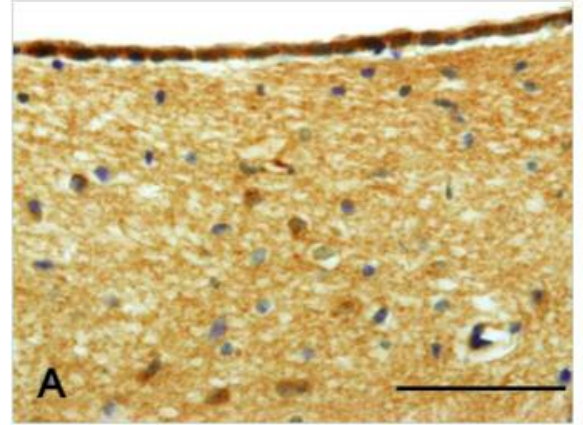

PVL

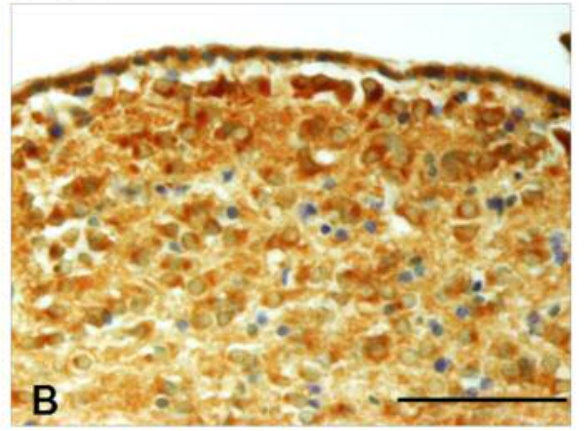

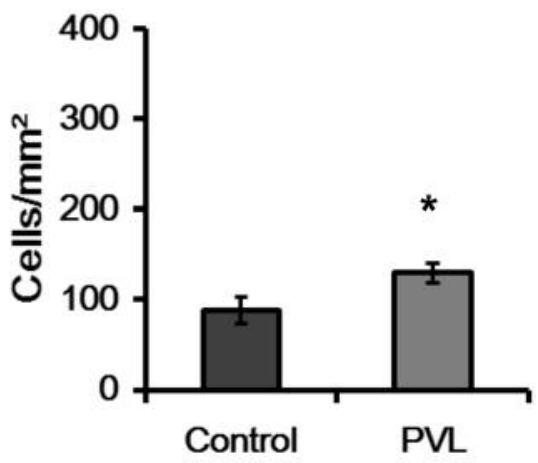

Figure 2. Representative photographs (A) and density (B) of nestin-immunoreactivity (IR) cells of in the subventricular zone (SVZ). The density of NestinIR cells was higher in the PVL group than in the control group. The data are expressed as mean and SEM values. *p $<0.05$. Scale bars=100 $\mu m$.

\section{Control}

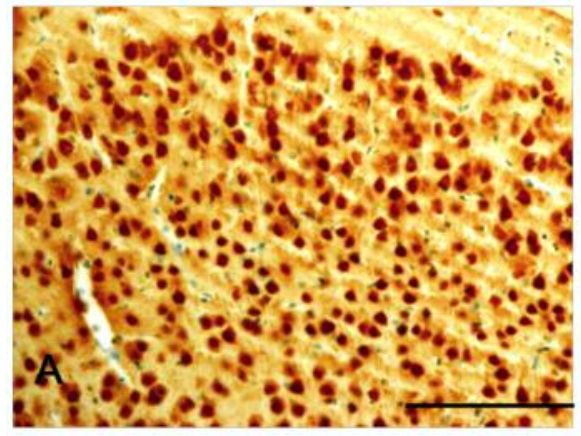

PVL

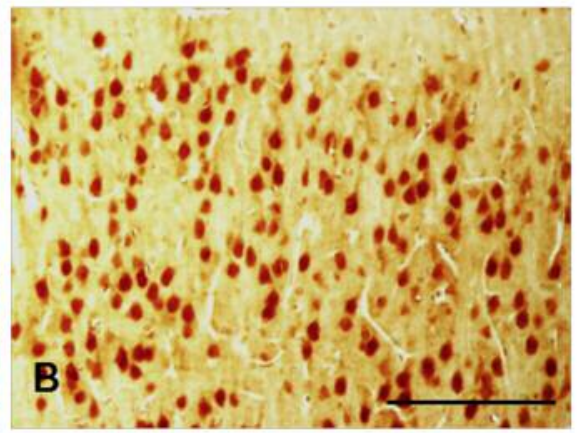

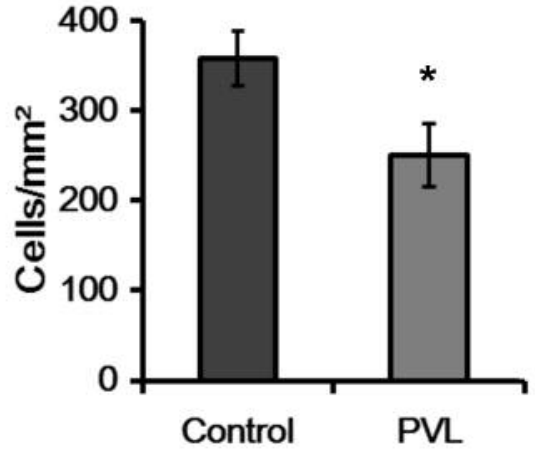

Figure 3. Representative photographs (A) and density (B) of NeuN-immunoreactivity (IR) cells in the cerebral parietal cortex. The cell densities in the cerebral cortex differ significantly between control and PVL groups. The data are expressed as mean and SEM values. ${ }^{*} p<0.05$. Scale bars $=100 \mu$ um.

\section{Control}

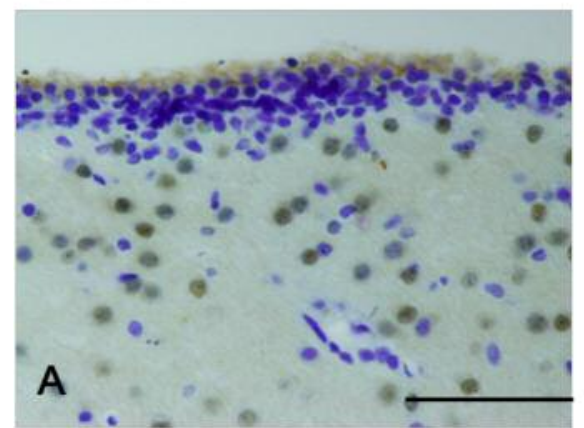

PVL

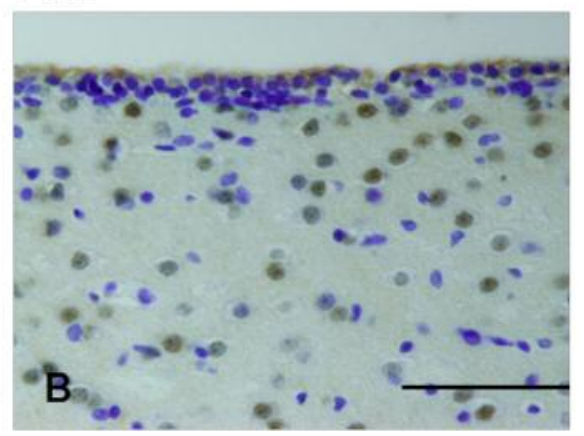

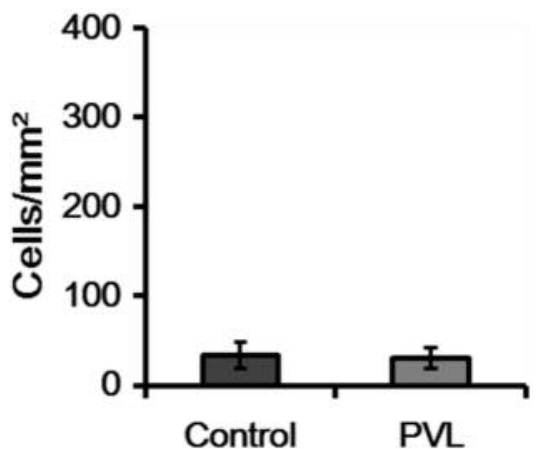

Figure 4. Representative photographs $(A)$ and density $(B)$ of immunoreactivity $(I R)$ cells in the subventricular zone. NeuN-IR cells were seen sparsely in the SVZ in control and PVL groups. The data are expressed as mean and SEM values. ${ }^{*} p<0.05$. Scale bars $=100 \mu m$. 
cortical neurogenesis is induced in cerebral cortex as in the SVZ in PVL model.

$\mathrm{NeuN}$ is a neuronal-specific nuclear protein (28). NeuN antibody was used to estimate the total numbers of neuronal and non-neuronal cells (29). The density of NeuN-IR cells in the cerebral cortex was significantly decreased in the PVL group. Similarly, premature infants with PVL have shown to present focal neuron loss in the frontal lobe (30). Later in childhood, some premature infants are reported to have persistent reduction in cortical volume $(31,32)$.

\section{Conclusion}

In summary, our results indicated that PVL results in decreased number neurons in the cerebral cortex despite evidence of increased neurogenesis. Given that progenitor cells in the SVZ migrate into the cortex, our results suggest that neurogenesis cannot compensate for the VPL-induced cerebral neuronal loss.

\section{Conflicts of Interest}

The Authors declare that they have no competing interests.

\section{Authors' Contributions}

Yonghyun Jun designed the study and participated in the surgical procedures. Hanbit Cho, Gyeong Hyeon Jo analyzed the obtained data. Yoonyoung Chung performed the immunohistochemistry. All Authors read and approved the final manuscript.

\section{Acknowledgements}

This study was supported by the 'Chosun University Research Aid Scholarship Program' for undergraduate students, 2017.

\section{References}

1 Ortinau $\mathrm{C}$ and Neil J: The neuroanatomy of prematurity: normal brain development and the impact of preterm birth. Clin Anat 28: 168-183, 2015. PMID: 25043926, DOI: 10.1002/ca.22430

2 Nosarti C, Nam KW, Walshe M, Murray RM, Cuddy M, Rifkin L and Allin MP: Preterm birth and structural brain alterations in early adulthood. Neuroimage Clin 6: 180-181, 2014. PMID: 25379430, DOI: 10.1016/j.nicl.2014.08.005

3 Botellero VL, Skranes J, Bjuland KJ, Haberg AK, Lydersen S, Brubakk AM, Indredavik MS and Martinussen M: A longitudinal study of associations between psychiatric symptoms and disorders and cerebral gray matter volumes in adolescents born very preterm. BMC Pediatr 17: 45, 2017. PMID: 28143492, DOI: $10.1186 / \mathrm{s} 12887-017-0793-0$

4 Lowe JR, Duncan AF, Bann CM, Fuller J, Hintz SR, Das A, Higgins RD and Watterberg KL: Early working memory as a racially and ethnically neutral measure of outcome in extremely preterm children at 18-22 months. Early Hum Dev 89: 10551061, 2013. PMID: 23993309, DOI: 10.1016/ j.earlhumdev. 2013.08.009
5 Chen HJ, Wei KL, Zhou CL, Yao YJ, Yang YJ, Fan XF, Gao XR, Liu XH, Qian JH, Wu BQ, Wu GQ, Zhang QM and Zhang XL: Incidence of brain injuries in premature infants with gestational age $</=34$ weeks in ten urban hospitals in China. World J Pediatr 9: 17-24, 2013. PMID: 23275107, DOI: 10.1007/s12519-012-0395-8

6 Liu XB, Shen Y, Plane JM and Deng W: Vulnerability of premyelinating oligodendrocytes to white-matter damage in neonatal brain injury. Neurosci Bull 29: 229-238, 2013. PMID: 23456565, DOI: 10.1007/s12264-013-1311-5

7 Yu T, Rong L, Wang Q, You Y, Fu JX, Kang LM and Wu YQ: Influence of neonatal diseases and treatments on the development of cerebral palsy in preterm infant. Sichuan Da Xue Xue Bao Yi Xue Ban 44: 270-273, 2013. PMID:23745270

8 Golden JA, Gilles FH, Rudelli R and Leviton A: Frequency of neuropathological abnormalities in very low birth weight infants. J Neuropathol Exp Neurol 56: 472-478, 1997. PMID: 9143259

9 Cheng T, Xue X and Fu J: Effect of OLIG1 on the development of oligodendrocytes and myelination in a neonatal rat PVL model induced by hypoxia-ischemia. Mol Med Rep 11: 23792386, 2015. PMID: 25435330, DOI: 10.3892/mmr.2014.3028

10 Salmaso N, Dominguez M, Kravitz J, Komitova M, Vaccarino FM and Schwartz ML: Contribution of maternal oxygenic state to the effects of chronic postnatal hypoxia on mouse body and brain development. Neurosci Lett 604: 12-17, 2015. PMID: 26222256, DOI: 10.1016/j.neulet.2015.07.033

11 Billiards SS, Haynes RL, Folkerth RD, Borenstein NS, Trachtenberg FL, Rowitch DH, Ligon KL, Volpe JJ and Kinney HC: Myelin abnormalities without oligodendrocyte loss in periventricular leukomalacia. Brain Pathol 18: 153-163, 2008. PMID: 18177464, DOI: 10.1111/j.1750-3639.2007.00107.x.

12 Wang H, Chung Y, Yu SK and Jun Y: The Immunoreactivity of PI3K/AKT Pathway After Prenatal Hypoxic Damage. In Vivo 31: 855-860, 2017. PMID: 28882951

13 Levison SW, Rothstein RP, Romanko MJ, Snyder MJ, Meyers RL and Vannucci SJ: Hypoxia/ischemia depletes the rat perinatal subventricular zone of oligodendrocyte progenitors and neural stem cells. Dev Neurosci 23: 234-247, 2001. PMID: 11598326

14 Chung YY, Jeon YH and Kim SW: Cortical neuronal loss after chronic prenatal hypoxia: a comparative laboratory study. J Korean Neurosurg Soc 56: 488-491, 2014. PMID: 25628808, DOI: $10.3340 / \mathrm{jkns} .2014 .56 .6 .488$

15 Derrick M, He J, Brady E and Tan S: The in vitro fate of rabbit fetal brain cells after acute in vivo hypoxia. J Neurosci 21: 138, 2001. PMID:11264330

16 Kinney HC, Haynes RL, Xu G, Andiman SE, Folkerth RD, Sleeper LA and Volpe JJ : Neuron deficit in the white matter and subplate in periventricular leukomalacia. Ann Neurol 71: 397406, 2012. PMID:22451205, DOI: 10.1002/ana.22612

17 Mao FX, Li WJ, Chen HJ, Qian LH and Buzby JS: White matter and SVZ serve as endogenous sources of glial progenitor cells for self-repair in neonatal rats with ischemic PVL. Brain Res 1535: 38-51, 2013. PMID: 23994449, DOI:10.1016/ j.brainres. 2013.08.006

18 Doetsch F, Caille I, Lim DA, Garcia-Verdugo JM and AlvarezBuylla A: Subventricular zone astrocytes are neural stem cells in the adult mammalian brain. Cell 97: 703-716, 1999. PMID: 10380923

19 So K, Chung Y, Yu SK and Jun Y: Regional Immunoreactivity of Pax6 in the neurogenic zone after chronic prenatal hypoxia. In Vivo 31: 1125-1129, 2017. PMID: 29102934 
20 Lois C and Alvarez-Buylla A: Proliferating subventricular zone cells in the adult mammalian forebrain can differentiate into neurons and glia. Proc Natl Acad Sci USA 90: 2074-2077, 1993. PMID: 8446631

21 von Bohlen and Halbach O: Immunohistological markers for proliferative events, gliogenesis, and neurogenesis within the adult hippocampus. Cell Tissue Res 345: 1-19, 2011. PMID: 21647561, DOI: $10.1007 / \mathrm{s} 00441-011-1196-4$

22 Schiffer D, Annovazzi L, Caldera V and Mellai M: On the origin and growth of Gliomas. Anticancer Res 30: 1977-1998, 2010. PMID: 20651342

23 Sarnat HB and Flores-Sarnat L: Neuropathology of pediatric epilepsy. Handb Clin Neurol 111: 399-416, 2013. PMID: 23622189, DOI: 10.1016/B978-0-444-52891-9.00044-0

24 Haynes RL, Xu G, Folkerth RD, Trachtenberg FL, Volpe JJ and Kinney HC: Potential neuronal repair in cerebral white matter injury in the human neonate. Pediatr Res 69: 62-67, 2011. PMID:20924315, DOI: 10.1203/PDR.0b013e3181ff3792

25 Okoshi Y, Mizuguchi M, Itoh M, Oka A and Takashima S: Altered nestin expression in the cerebrum with periventricular leukomalacia. Pediatr Neurol 36: 170-174, 2007. PMID: 17352950

26 Zhao C, Deng W and Gage FH: Mechanisms and functional implications of adult neurogenesis. Cell 132: 645-660, 2008 PMID: 18295581 doi: 10.1016/j.cell.2008.01.033

27 Fagel DM, Ganat Y, Silbereis J, Ebbitt T, Stewart W, Zhang H, Ment LR and Vaccarino FM: Cortical neurogenesis enhanced by chronic perinatal hypoxia. Exp Neurol 199: 77-91, 2006. PMID: 15916762
28 Mullen RJ, Buck CR and Smith AM: NeuN, a neuronal specific nuclear protein in vertebrates. Development (Cambridge, England) 116: 201-211, 1992. PMID: 1483388

29 Herculano-Houzel S and Lent R: Isotropic fractionator: a simple, rapid method for the quantification of total cell and neuron numbers in the brain. J Neurosci 25: 2518-2521, 2005. PMID: 15758160

30 Pierson CR, Folkerth RD, Billiards SS, Trachtenberg FL, Drinkwater ME, Volpe JJ and Kinney HC: Gray matter injury associated with periventricular leukomalacia in the premature infant. Acta Neuropathol 114: 619-631, 2007. PMID: 17912538

31 Peterson BS, Anderson AW, Ehrenkranz R, Staib LH, Tageldin M, Colson E, Gore JC, Duncan CC, Makuch R and Ment LR: Regional brain volumes and their later neurodevelopmental correlates in term and preterm infants. Pediatrics 111: 939-948, 2003. PMID: 12728069

32 Woodward LJ, Moor S, Hood KM, Champion PR, Foster-Cohen $\mathrm{S}$, Inder TE and Austin NC: Very preterm children show impairments across multiple neurodevelopmental domains by age 4 years. Arch Dis Child Fetal Neonatal Ed 94: 339-344, 2009. PMID: 19307223, DOI: 10.1136/adc.2008.146282

Received December 27, 2018

Revised January 17, 2019

Accepted January 21, 2019 